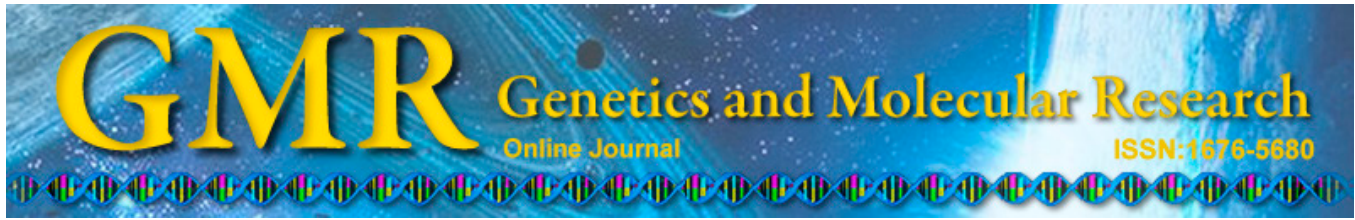

\title{
Antibody study in canine distemper virus nucleocapsid protein gene-immunized mice
}

\author{
B. Yuan, X.Y. Li, T. Zhu, L. Yuan, J.P. Hu, J. Chen, W. Gao and W.Z. Ren \\ College of Animal Sciences, Jilin University, Changchun, China
}

Corresponding author: W.Z. Ren

E-mail: renwzfml@163.com

Genet. Mol. Res. 14 (2): 3098-3105 (2015)

Received April 5, 2014

Accepted October 11, 2014

Published April 10, 2015

DOI http://dx.doi.org/10.4238/2015.April.10.20

\begin{abstract}
The gene for the nucleocapsid (N) protein of canine distemper virus was cloned into the pMD-18T vector, and positive recombinant plasmids were obtained by enzyme digestion and sequencing. After digestion by both EcoRI and KpnI, the plasmid was directionally cloned into the eukaryotic expression vector pcDNA; the positive clone pcDNA-N was screened by electrophoresis and then transfected into COS-7 cells. Immunofluorescence analysis results showed that the canine distemper virus $\mathrm{N}$ protein was expressed in the cytoplasm of transfected COS-7 cells. After emulsification in Freund's adjuvant, the recombinant plasmid pcDNA-N was injected into the abdominal cavity of 8-week-old BABL/c mice, with the pcDNA original vector used as a negative control. Mice were immunized 3 times every 2 weeks. The blood of immunized mice was drawn 2 weeks after completing the immunizations to measure titer levels. The antibody titer in the pcDNA-N test was $10^{1.62 \pm 0.164}$, while in the control group this value was $10^{0.52 \pm 0.56}$, indicating that specific humoral immunity was induced in canine distemper virus nucleocapsid proteinimmunized mice.
\end{abstract}

Key words: Canine distemper virus; Eukaryotic expression; Gene immunity 


\section{INTRODUCTION}

Canine distemper virus (CDV) belongs to the Morbillivirus genus, Paramyxoviridae family, and induces an acute, highly contagious disease in the Canidae, Felidae, Mustelidae, Viverridae, and some members of the raccoon family. This disease is very harmful to the kennel industry, fur animal breeding industry, and wildlife conservation industry, with a fatality rate of $80 \%$ and ferret fatality rate of $100 \%$ (Yin and Liu, 1997). With ecological and environmental changes, the natural hosts of CDV have expanded to 8 families of Carnivora and even to humans. In recent years, the prevention of this disease has mainly depended on inoculation with an attenuated vaccine. Although CVD prevention has been effective, potential hazards with a certain degree of immune inhibition and nervous system damage still exist (Chappuis, 1995; Pardo et al., 1997).

Traditional vaccines are produced using a complete virus, and thus some components are not related to specific immunity, which can induce local or systemic adverse reactions. Furthermore, attenuated vaccines can cause artificial virus spreading and virulence atavism, limiting the traditional application of some vaccines. Currently, some progress has been made in studies on genetic engineering of a CDV vaccine that is safer than the traditional vaccine (Kerdiles et al., 2006; Rubin and Levin, 2009; Jensen et al., 2009); however, there are few reports from China (Jian et al., 2008; Zhang et al., 2008). DNA vaccine, which includes nucleic acid vaccines, is a technology developed in the 1990s. This type of vaccine is used to inoculate eukaryotic genes encoding antigen proteins into animals; a vector will express the target antigen protein through the host transcription system to induce an immune response against the antigen for prevention and therapy (Fischer et al., 2003; Plattet et al., 2005; Wang et al., 2010). DNA immunity comprehensively induces an organism's immune system, simulating natural viral infection and inducing the organism to produce specific body fluids and cellular immune responses to protect against the antigen, with both high efficiency of attenuated vaccine and safety of the inactivated vaccine (Xue et al., 2006).

A CDV nucleocapsid $(\mathrm{N})$ protein recombinant plasmid was constructed in this study. The vector was transfected into cells and shown to be stably expressed in mice. Our results can be expanded for CDV prevention.

\section{MATERAL AND METHODS}

\section{Vaccine}

Vaccine CDV/R/20-8 was provided by Wuxing Animal Health Medicine Factory in Jilin Province, inoculated into Vero cells at $1 \%$, and collected when the cytopathic effect was approximately $80 \%$. Cellular debris was removed by freezing at $-20^{\circ} \mathrm{C}$ and thawing 3 times followed by centrifugation at $89,000 \mathrm{~g}$. The pellet was suspended in phosphate-buffered saline and frozen.

\section{Strains and plasmids}

The Escherichia coli JM109 strain was preserved in our laboratory. The pMD-18T vector and pcDNA vector were purchased from Promega (Madison, WI, USA). COS-7 cells (transformed African green monkey nephrocytes by SV40) were used for transfection and purchased from the Institute of Biochemistry and Cell Biology (Shanghai, China) and Chinese Academy of Sciences (Beijing, China). 


\section{Reagents}

The RNAPCR Kit(AMV) Ver. 3.0 reverse transcription kit was purchased from TaKaRa (Shiga, Japan); the viral RNA Kit was purchased from OMEGA Bio-Tek (Norcross, GA, USA); T4 DNA ligase, EX Taq polymerase, dNTP mixture, isopropyl $\beta$-D-1-thiogalactopyranoside, $\mathrm{X}$-Gal, $\lambda$-EcoT14I marker, DNA Gel Extraction Kit, and transfection kit (Lipofectamine ${ }^{\mathrm{TM}}$ 2000) were purchased from Takara Biotechnology Co., Ltd. (Dalian, China) The E.Z.N.A. ${ }^{\circledR}$ HP Plasmid Midi Kit (OMEGA Bio-Tek) was used for large-scale plasmid extraction. Other agents were imported or domestic analytical reagents.

\section{Experimental animals}

BALB/c mice were purchased from Norman Bethune University of Medical Science.

\section{Virus gene amplification and cloning}

RNA extraction was conducted according to the Viral RNA Kit (OMEGA) instructions.

\section{Primer design and synthesis}

The primer pair was designed based on the $\mathrm{N}$ gene sequence in the CDV genome (Seq. No. AF014953.1) recorded in GenBank: S1: 5'-TGAATTCGGGGAGCAATAAGAGGA ATA-3'; S2: 5'-ANNGAATTCNNCCAAGATAACCATGTACG-3'. The primers containing EcoRI and $K p n I$ restriction sites were synthesized by Shanghai Sangon Company (Shanghai, China).

\section{Reverse transcription-polymerase chain reaction (RT-PCR)}

Extracted RNA was used for cDNA synthesis according to TaKaRa RNA PCR Kit (AMV) Ver. 3.0 instructions. The PCR system included: $6.5 \mu \mathrm{L}$ double-distilled water, $5 \mu \mathrm{L}$ 10X PCR buffer, $4 \mu \mathrm{L} 2.5 \mathrm{mM}$ dNTP mix, $1 \mu \mathrm{L} 10 \mu \mathrm{M}$ forward and reverse primers, $2 \mu \mathrm{L}$ cDNA template, and $0.5 \mu \mathrm{L} 5 \mathrm{U} / \mu \mathrm{L}$ Taq DNA polymerase. The following reaction conditions were used: $95^{\circ} \mathrm{C}$ for $4 \mathrm{~min} ; 94^{\circ} \mathrm{C}$ for $30 \mathrm{~s}, 59^{\circ} \mathrm{C}$ for $30 \mathrm{~s}$, and $72^{\circ} \mathrm{C}$ for $40 \mathrm{~s}$ for $35 \mathrm{cycles}$, followed by $72^{\circ} \mathrm{C}$ for $10 \mathrm{~min}$.

PCR product extraction and purification were conducted according to extraction kit (Axygen, Union City, CA, USA) instructions. The target segment was ligated into the pMD$18 \mathrm{~T}$ vector overnight at $16^{\circ} \mathrm{C}$. The ligation reaction system included $0.5 \mu \mathrm{L}$ pMD- $18 \mathrm{~T}$ vector, $4.5 \mu \mathrm{L}$ inserted target segment, and $5 \mu \mathrm{L}$ ligation mixture in a total volume of $10 \mu \mathrm{L}$.

\section{$\mathrm{N}$ protein gene clone and identification}

The ligation product was added into freeze-thawed competent cells on ice for $45 \mathrm{~min}$, heat-shocked at $42^{\circ} \mathrm{C}$ for $2 \mathrm{~min}$, and placed in an ice bath for $5 \mathrm{~min}$. The transformed cells were added to $890 \mu \mathrm{L}$ Luria-Bertani (LB) medium and oscillated at $120 \mathrm{rpm}$ for $30 \mathrm{~min}$. Next, $200 \mu \mathrm{L}$ transformed cells were coated onto $\mathrm{LB}$ solid medium and incubated at $37^{\circ} \mathrm{C}$ for 12 
h. Single colonies were selected from LB solid medium, inoculated into $5 \mathrm{~mL}$ LB liquid medium containing ampicillin, and oscillated at $37^{\circ} \mathrm{C}$ for $12 \mathrm{~h}$. Transformed bacteria were used as a template for PCR. The $50-\mu \mathrm{L}$ reaction system contained: $38 \mu \mathrm{L}$ double-distilled water, 5 $\mu \mathrm{L} 10 \mathrm{X}$ PCR buffer, $4 \mu \mathrm{L} 2.5 \mathrm{mM}$ dNTPs, $1 \mu \mathrm{L} 10 \mu \mathrm{M}$ forward and reverse primers, $0.5 \mu \mathrm{L}$ bacterial solution, and $0.5 \mu \mathrm{L} 5 \mathrm{U} / \mu \mathrm{L}$ Taq DNA polymerase. Positive clones were detected by agarose electrophoresis and identified by sequencing.

\section{Subcloning and transfection}

The target gene cloned into pMD-18T was extracted by double-enzyme digestion with EcoRI and KpnI and purified according to the Axygen extraction kit instructions. The gene was ligated into the eukaryotic expression vector pcDNA using conventional methods, and positive pcDNA-N clones were screened and analyzed by restriction enzyme digestion.

Transfection was conducted according to the transfection kit Lipofectamine ${ }^{\mathrm{TM}} 2000$ instructions, with the original pcDNA vector used as a negative control. An indirect immunofluorescence assay was used to confirm the results. The serum of mice immunized by CDV recombinant $\mathrm{N}$ gene product expressed in $E$. coli was used as the primary antibody; goat anti-mice IgG labeled by fluorescein isothiocyanate was used as the second antibody. The results were observed and recorded under an inverted fluorescence microscope. Recombinant plasmid amplification and purification were conducted according to the E.Z.N.A. ${ }^{\circledR}$ HP Plasmid Midi Kit instructions.

\section{DNA immune}

Twenty BALB/c female mice that were 8 weeks old were divided into 2 groups (pcDNA-N-injected group and original pcDNA-injected group); complete emulsion of 100 $\mu \mathrm{g}$ plasmid DNA and $100 \mu \mathrm{L}$ Freund's adjuvant (1:1) were injected into mouse abdomens. These mice were immunized 3 times at intervals of 2 weeks, and their blood was extracted to separate the serum 2 weeks after completing the immunization.

\section{Serum anti-N antibody titer detected using enzyme-linked immunosorbent assay (ELISA)}

Reaction conditions were determined based on previous studies (Waner et al., 2003). The $\mathrm{OD}_{490}$ value was measured after the reaction. Titers were calculated at the serum maximum dilution ratio when $\mathrm{P} / \mathrm{N} \geq 2.0$.

\section{RESULTS}

\section{Virus proliferation results}

Vero cells were inoculated with CDV when they had covered the plate in a monolayer. A cytopathic effect occurred after incubation with $5 \% \mathrm{CO}_{2}$ at $37^{\circ} \mathrm{C}$ for $3-4$ days, including enhanced refraction, cell dragnet, agglutination, and abscission (Figure 1). 

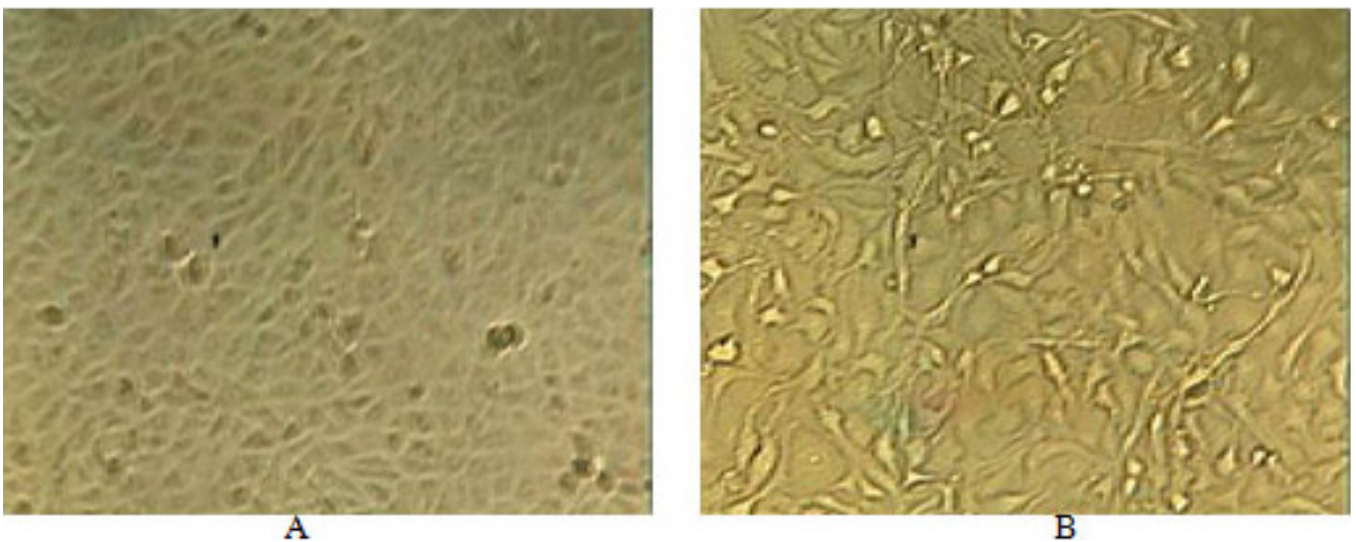

Figure 1. CDV production in vitro cytopathic effects (CPE) $(10 \times 10)$. A. Normal Vero cell. B. CPE cell.

\section{N gene RT-PCR amplification product identification results}

Based on the known CDV N gene sequence, RT-PCT amplification was conducted and the amplified segment length was consistent with the expected length of 1572 bp (Figure 2).

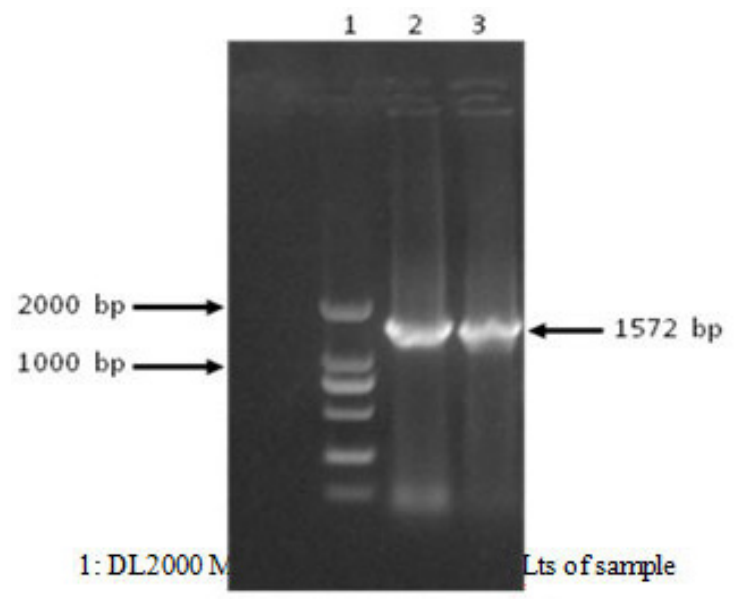

Figure 2. N gene RT-PCR results.

\section{$\mathrm{N}$ gene clone and sequencing identification results}

The bacterial solution identified by PCR was sequenced bidirectionally by Shanghai SANGON Biotechnology Co., Ltd. to ensure sequence accuracy. A 1572-bp sequence was obtained. This sequence was aligned with AF014953.1, and identity was found to be $99.1 \%$, indicating that cloning was successful.

\section{Recombinant pcDNA-N expression in COS-7 cells}

After purification, recombinant pcDNA-N was transfected into COS-7 cells, fixed 
with acetone/ethanol (3:2) $48 \mathrm{~h}$ after transfection, and expression was verified using an immunofluorescence assay. Specific fluorescence appeared in pcDNA-N-positive cells (Figure 3A), while no fluorescence was observed in negative control cells containing the empty plasmid (Figure 3B). Thus, the recombinant plasmid was expressed in vitro.
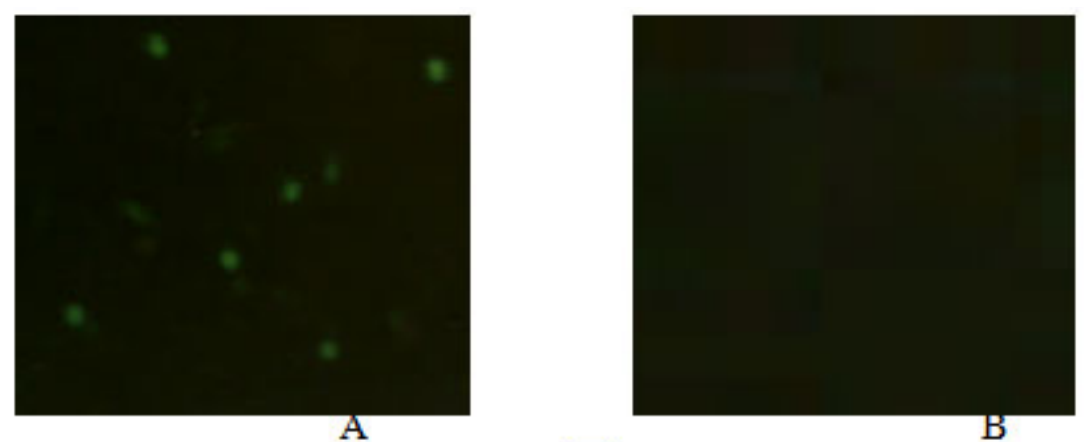

Figure 3. Immunofluorescence assay of pcDNA-N transfection of CDV N gene expression in COS7 cells (200X). A. Detection of plasmid pcDNA-N by IFA. B. Negative control.

\section{ELISA detection results for antibody induced by recombinant plasmid in mice}

The pcDNA-N and pcDNA empty vector DNA were injected into the abdomens of 20 8 -week-old BALB/c female mice. Mouse blood was extracted to separate the serum 2 weeks after completing the immunization, and the specific antibody was detected using ELISA (Figure 4). Figure 3 shows that pcDNA-N DNA generated the antibody with a titer of $10^{1.62 \pm 0.164}$, while the antibody with titer of only $10^{0.52 \pm 0.56}$ was detected in the negative control group, which was considered a non-specific background reaction.

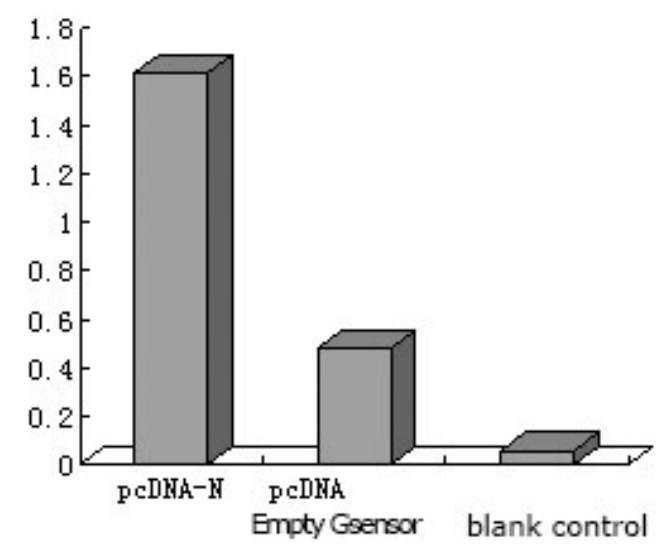

Figure 4. pcNDA-N and pcDNA original carrier gene immune BALB/c mice after ELISA to detect CDV antibody titer.

\section{DISCUSSION}

Canine distemper is a highly contagious disease caused by CDV and is harmful to Canidae and other Carnivora animals. Viral proteins include nucleocapsid (N) protein, phos- 
phoprotein, matrix membrane protein, fusion protein, and attachment protein; among these, the $\mathrm{N}$ protein is a structural protein with the highest content in the virus structure and plays a regulatory role in virus assembly, transcription, and duplication. $\mathrm{N}$ is an immunogenicity protein with the highest conservation and can induce a strong antibody reaction upon viral infection (Kibirev et al., 2010). In addition, the $\mathrm{N}$ protein contains $\mathrm{T}$ cell epitopes, which play an important role in the cell immune system. CDV toxicity is closely related to the $\mathrm{N}$ protein, and plays an important role in persistent infection of the central nervous system (Jensen et al., 2009; Fukumoto et al., 2009). The $\mathrm{N}$ protein is the immunogenicity protein showing the strongest conservation in CDV without a glycosylation site. Therefore, the CDV/R/20-8 strain was used; the gene encoding the virus $\mathrm{N}$ protein was inserted into the eukaryotic expression vector pcDNA3.1; recombinant plasmid pcDNA-N was constructed to examine the CDV DNA vaccine.

Recombinant eukaryotic expression vector pcDNA-N was transfected in vitro to verify its expression, amplified for cultivating, purified, emulsified completely with Freund's adjuvant, and injected into BALB/c mice. pcDNA-N induced the ELISA antibody at higher levels with a titer of $10^{1.62 \pm 0.164}$, which is consistent with the Sixt (1998) report that the constructed $\mathrm{pVIJ}-\mathrm{F}$ and $\mathrm{pVIJ}-\mathrm{H}$ recombinant plasmids induced an immune response after immunization of mice by gene gun and intramuscular injection. Xu et al. (2003) reported that capsular glycoprotein genes $\mathrm{F}$ and $\mathrm{H}$ were cloned for eukaryotic expression and induced an immune response through intramuscular injection with polyethyleneimine as an adjuvant. During the immune response in this study, other inoculating methods were explored but the results were similar, and immune adjuvant screening should be further examined. We found that the constructed recombinant plasmid pcDNA-N was expressed and showed biological activity in mice, providing a foundation for further experiments in Canidae.

\title{
ACKNOWLEDGMENTS
}

\author{
Research supported by the National Key Technology R\&DProgram(\#2015BAJY2602).
}

\section{REFERENCES}

Chappuis G (1995). Control of canine distemper. Vet. Microbiol. 44: 351-358.

Fischer L, Tronel JP, Minke J, Barzu S, et al. (2003). Vaccination of puppies with a lipid-formulated plasmid vaccine protects against a severe canine distemper virus challenge. Vaccine 21: 1099-1102.

Fukumoto S, Tamaki Y, Igarashi I, Suzuki H, et al. (2009). Immunogenicity and growth inhibitory efficacy of the primeboost immunization regime with DNA followed by recombinant vaccinia virus carrying the P29 gene of Babesia gibsoni in dogs. Exp. Parasitol. 123: 296-301.

Jensen TH, Nielsen L, Aasted B and Blixenkrone-Moller M (2009). Early life DNA vaccination with the H gene of Canine distemper virus induces robust protection against distemper. Vaccine 27: 5178-5183.

Jian ZY, Yia Y, Wang QK, et al. (2008). Canine distemper N nuclear capsid protein gene eukaryotic expression and identification. Zhong Guo Nong Xue Tong Bao 8-12.

Kerdiles YM, Cherif B, Marie JC, Tremillon N, et al. (2006). Immunomodulatory properties of morbillivirus nucleoproteins. Viral Immunol. 19: 324-334.

Kibirev I, Drobkov BI and Marakulin IV (2010). Problems and prospects of gene therapeutics and DNA vaccines development and application. Patol. Fiziol. Eksp. Ter. 1: 35-40.

Litster A, Nichols J and Volpe A (2012). Prevalence of positive antibody test results for canine parvovirus (CPV) and canine distemper virus (CDV) and response to modified live vaccination against CPV and CDV in dogs entering animal shelters. Vet. Microbiol. 157: 86-90.

Pardo MC, Bauman JE and Mackowiak M (1997). Protection of dogs against canine distemper by vaccination with a 
canarypox virus recombinant expressing canine distemper virus fusion and hemagglutinin glycoproteins. Am. J. Vet. Res. 58: 833-836.

Plattet P, Rivals JP, Zuber B, Brunner JM, et al. (2005). The fusion protein of wild-type canine distemper virus is a major determinant of persistent infection. Virology 337: 312-326.

Rubin DJ and Levin RM (2009). Neurologic complications of Paget disease of bone. Endocr. Pract. 15: 158-166.

Sixt N, Cardoso A, Vallier A, Fayolle J, et al. (1998). Canine distemper virus DNA vaccination induces humoral and cellular immunity and protects against a lethal intracerebral challenge. J. Virol. 72: 8472-8476.

Waner T, Mazar S, Nachmias E, keren-Komblatt E, et al. (2003). Evaluation of a dot ELISA kit for measuring immunoglobulin M antibodies to canine parvovirus and distemper virus. Vet. Rec. 152: 588-591.

Wang L, Guo F, Wei S and Zhao R (2010). Neonatal intramuscular injection of plasmid DNA encoding GLP-1 reduces serum insulin level and modifies skeletal muscle myosin heavy chain composition in adult rats. Physiol. Res. 59: 571-579.

Xu XM, Cui ZZ, Yin J, Yang L, et al. (2003). Antibody response in mice induced by CDV envelope glycoprotein gene of Chinese isolate. Chin. J. Prev. Vet. Med. 25: 419-423.

Xue CL, Mao DG, Cao SX, et al. (2006). Somatostatin, passive and active immune and genetic research progress. Zhong Guo Nong Xue Tong Bao 9-13.

Yin Z and Liu JH (1997). Animal virology. Ke Xue Chu Ban She 756-757.

Zhang L, Hua YP, Zeng XW, et al. (2008). Fox raccoon source of canine distemper fusion protein gene homology analysis. Dong Bei Lin Ye Da Xue Xue Bao 70-72. 